\title{
Aprendizagem autônoma na formação de intérpretes de conferência: usando a pesquisa-ação para aperfeiçoamento da prática pedagógica
}

Anelise Freitas Pereira Gondar*

\section{Introdução}

O ofício da interpretação de conferência não apenas se consolidou de forma indispensável no contexto da comunicação intercultural pós-Nuremberg, como também, ao longo das 60 décadas de massificação e visibilização da interpretação, contribuiu para ampla pesquisa voltada às técnicas, ao desempenho, à qualidade e ao aperfeiçoamento da formação (Pöchhacker, 2007; Gile, 2009). Assim, é possível afirmar que a pesquisa tanto em Interpretação de Conferências como em outras modalidades de interpretação no mundo, desenvolvida ao longo dos anos de desenvolvimento da profissão frequentemente por intérpretes profissionais atuantes no ensino e pesquisa, pode ser considerada uma área de investigação já consolidada tanto em grandes centros de formação de tradutores e intérpretes em instituições norte-americanas e europeias quanto em diversos departamentos de linguística aplicada (Gile, 2009).

Os cursos de formação em interpretação são não apenas locus primordial de aquisição das técnicas, mas também o local de interação entre alunos e professores que permite a construção de uma comunidade epistêmica. Os cursos exercem papel fundamental para a consolidação da profissão e para a imagem do ofício: são eles os locais primordiais de desenvolvimento da capacidade profissional do futuro intérprete e podem

\footnotetext{
* Anelise F.P. Gondar é professora do Departamento de Letras Anglo-Germânicas do Instituto de Letras (ILE) da Universidade do Estado do Rio de Janeiro (Uerj) e do Curso de pós-graduação lato sensu Formação de Intérpretes de Conferências da PUC-Rio.
} 
adequar seus conteúdos e metodologias à própria evolução das demandas, do mercado de trabalho e também dos perfis de aluno. Reconhecendo, portanto, a centralidade dos cursos de formação e também o desafio a que estão submetidos professores e alunos em seu saber-fazer, este artigo tem como tema principal a relevância da pesquisa-ação para o desenvolvimento curricular e didático-metodológico dos cursos de interpretação. Justifica-se a relevância da abordagem da pesquisa-ação para a formação em interpretação a partir do valor que esta tem para o desenvolvimento da pesquisa em educação em geral e da formação de intérpretes em particular. Identificadas as linhas gerais da pesquisa-ação e evidenciadas a partir da literatura especializada as suas aplicações em cursos de formação de intérpretes, este artigo propõe, a partir da descrição e análise da mudança da ementa de uma das disciplinas obrigatórias do curso de interpretação da PUC-Rio, apresentar e analisar insumos que mostram que, sem a pesquisaação, muitas mudanças incrementais não teriam sido levadas a cabo. Com a apresentação da proposta curricular nova, este artigo pretende lançar luz ao caráter dinâmico da concepção curricular quando voltada não apenas para a formação de intérprete que domine as técnicas básicas do ofício, mas que também seja capaz de desenvolver faculdades de aperfeiçoamento autônomo baseadas em autorreflexividade.

\section{O caráter teórico-prático da formação em interpretação de conferências}

A atividade interpretatória tem um percurso histórico singular e intrinsecamente relacionado à evolução das necessidades comunicativas da humanidade. Pesquisas historiográficas dedicadas à presença e atuação de intérpretes na América Latina ao longo dos séculos evidenciam tanto 
agências quanto resistências relacionadas à atividade de mediação linguística em diversos contextos da investida colonizatória ${ }^{1}$.

A natureza do ofício, intrinsecamente relacionada à atividade de seus praticantes, ganharia novos contornos a partir do marco fundacional da interpretação com uso de tecnologias que se dá durante os tribunais de Nuremberg, ao final da Segunda Guerra mundial. Se a tecnologia passa a ser a condição de possibilidade para a solidificação da profissão em contextos de comunicação internacional como em conferências das Nações Unidas e em outros órgãos de representação na Comunidade Internacional, seus primeiros profissionais são alçados à condição de formadores. A escola de Paris, segundo Pöchhacker, teria um papel fundamental não apenas na definição do perfil do ofício da interpretação, mas também na teorização de diversos sub-elementos da atividade tradutória que serviriam de matriz de conhecimento a outras instituições de formação criadas posteriormente. Assim, a teoria do sentido de Seleskovitch², as compreensões acerca do papel do intérprete de Taylor-Bouladon (2000) e a compreensão de qual deveria ser o perfil ideal do intérprete, de Herbert (1957), estabeleceram em larga medida as balizas do campo intelectual da interpretação. Além disso, a racionalidade de transmissão de conteúdos e técnicas obedecera à lógica particularista e prática da tutoria individualizada, ou seja, uma transmissão do conhecimento em que

\footnotetext{
1 Ver, para tanto, a pesquisa realizada por Dennys Silva-Reis em relação à atividade tradutória e interpretatória no contexto pan-latino-americano em http://historiografiadatraducaobr.blogspot.com.br/ (Acesso em 07 jul. 2017).

2 Ver, para uma atualização da discussão, o artigo de MOUZOURAKIS. Panayotis. "How do we interpret?" aiic.net. 21/03/2005 Em: <http://aiic.net/p/1739> (Acesso em 09 jul. 2017).
} 


\begin{abstract}
uma primeira geração de professores de interpretação, eles mesmos profissionais bem-sucedidos, estabeleceu uma tradição duradoura de treinamento através de ensino-aprendizagem acompanhada, ou seja, uma transferência de know-how de mestre a aprendiz através de exercícios que simulassem as atividades na vida real (Pöchhacker, 2007, pp. 177-178) ${ }^{3}$. (Esta e todas as outras traduções são nossas)
\end{abstract}

Não apenas isso, mas também baseada em larga medida no que Adams (2011) denominou um fixed mindset, ou seja, uma compreensão de que a capacidade interpretatória estaria baseada em aspectos biológicos e deveria, portanto, ser desenvolvida a partir do pendor natural para o desempenho do ofício.

A riqueza de conhecimento construído na prática pedagógica em sala de aula, portanto, segundo Pöchhacker, tem características singulares, típicas do estabelecimento de princípios básicos sobre os quais uma série de teóricos de segunda geração construiria conhecimento. Após algumas décadas de pesquisa em interpretação e da ampliação da oferta de cursos tanto universitários quanto comerciais de formação, Pöchacker afirma que “a pedagogia da interpretação tem gerado pouca pesquisa sistemática - por outro lado, comparativamente, um grande volume de descrições de experiências" (2007, p. 177) .

Fornecendo uma memória da evolução da formação na área, ele afirmará que

\footnotetext{
${ }^{3}$ First-generation teachers of interpreting, themselves accomplished professionals, established a lasting tradition of training by apprenticeship; that is, transfer of know-how and professional knowledge from master to student by exercises modeled on real-life tasks.

${ }^{4}$ The pedagogy of interpreting has generated little systematic investigation but a comparatively large body of experiential description.
} 


\begin{abstract}
uma reflexão sistemática acerca de questões curriculares permaneceu limitada até as décadas de 1980 e 1990 quando a tradição do ensino de interpretação de conferência fortemente baseada no desempenho do ofício passou a ser complementada por abordagens científicas, orientadas ao processo. Novas necessidades em termos de formação voltada para cenários comunitários reforçaram a importância do currículo como uma estrutura organizacional definidora e orientadora da prática pedagógica (Pöchhacker, 2007, p. 177)5.
\end{abstract}

Com a evolução dos cursos de interpretação e também a apropriação de metodologias da área da educação adequadas às demandas gerais de ensino-aprendizagem contemporâneas em nível mundial, Pöchhacker apresenta elementos fundamentais à formação do intérprete hoje, quais sejam, “a 'cognição situada', a 'prática refletida' e a 'aprendizagem cognitiva', que podem servir de base a um aperfeiçoamento de práticas de formação de intérpretes já estabelecidas, no sentido de serem mais orientadas ao aluno e à interação" (Pöchhacker, 2007, p. 177) ${ }^{6}$.

\title{
3. Da validade da pesquisa-ação para o estudo da interpretação de conferências
}

Diante do caráter teórico-prático da formação em interpretação de conferência, a pesquisa-ação apresenta-se como possibilidade de avanço do

\footnotetext{
${ }^{5}$ Systematic reflection on curricular issues remained very limited until the 1980s and 1990s, when the strongly profession-based tradition of conference interpreter training was complemented by a scientific, process-oriented approach, and new training needs for interpreting in community-based settings highlighted the role of the curriculum as an organizational structure framing and guiding teaching practice.

${ }^{6}[\ldots]$ 'situated cognition', 'reflective practice' and 'cognitive apprenticeship' [which] can be used to underpin a more student-oriented and interaction-oriented refinement of established interpreter training practices.
} 
conhecimento em interpretação e de aprimoramento da própria dinâmica de ensino-aprendizagem em sala de aula.

Tendo surgido no contexto da pesquisa em educação e sendo ao longo dos anos amplamente utilizada em diversas áreas do conhecimento (Cohen et al., 2007, p. 297), dentre elas a área do ensino e aquisição de língua estrangeira, a pesquisa-ação "tem sido especial e amplamente utilizada em inovação curricular nas áreas da educação, aquisição de língua estrangeira, ensino de línguas e, mais recentemente, na formação de intérpretes" (Slatyer, 2006, apud Hale \& Napier, 2014, p.186)7.

O que é então a pesquisa-ação? Em linhas gerais, a pesquisa-ação está associada à identificação de um cenário social dado e ao levantamento de elementos desse cenário que podem ser aperfeiçoados a partir da visita a pesquisas anteriores sobre o assunto, da reflexão sobre a temática e da proposição da modificação de aspectos da prática (pedagógica) que aproximem o pesquisador (ou professor) de uma prática mais relevante naquele contexto. $\mathrm{Na}$ área do ensino de interpretação de conferências, ao lado de pesquisas qualitativas de cunho experimental, a pesquisa-ação também tem fornecido insumos interessantes para a possibilidade de desenvolvimento, em sala de aula, de qualidade e expertise através de técnicas de prática deliberada (Ericsson, 2000), bem como do aperfeiçoamento de mecanismos de aprendizagem cooperativa (Krouse, 2010) e, no contexto da atividade tradutória, da aprendizagem reflexiva (Shih, 2011).

\footnotetext{
7 [action research] has particularly been used extensively in curriculum innovation in the fields of education, second language acquisition and language teaching and more recently in interpreter education.
} 
As técnicas que compõem a pesquisa-ação permitem a validação dos resultados de pesquisa através de um processo em espiral no qual em primeira instância identifica-se o problema ou o elemento da prática pedagógica a ser aprimorado; a seguir, faz-se um planejamento com vistas a abordar o problema; em seguida há a coleta de dados ou informações a partir da literatura especializada que permitam enxergar se/como o problema já foi solucionado em outro contexto de ensino-aprendizagem e quais as limitações envolvidas; e, por último, há a implementação e documentação das mudanças com vistas ao alcance do resultado final. Nas palavras de Scott (1999, apud Hale \& Napier, 2014, p. 186), todos os passos da pesquisa-ação envolvem uma atividade reflexiva. Sua iteração, conforme preceitos da pesquisa acadêmica, forja a possibilidade de avanço do conhecimento na área em questão. Assim, a pesquisa-ação envolve

ciclos repetidos e reflexivos de planejamento, coleta de informações e dados e implementação denominados de 'espiral' da pesquisa-ação (Burns, 2010), e o processo de reflexão compreende quatro etapas: a identificação do problema, a leitura acerca do problema (por ex., por meio de revisão bibliográfica, coleta de dados, análise), o engajamento com o problema (realização de recomendações de mudança) e a ação sobre o problema (implementação) (Scott, 1999, apud Hale \& Napier, 2014, pp. $186-187)^{8}$.

${ }^{8}[\ldots]$ repetitive, reflective cycles of planning, information gathering/data collection and implementation referred to as the action research 'spiral' (Burns, 2010), and the reflective process involves four key stages: sensing the problem, reading the problem (e.g. literature review, data collection, analysis), matching the problem (making recommendations for change) and acting on the problem (implementation). 
Nesse sentido, a pesquisa-ação, longe de ser uma metodologia paracientífica, é capaz de "enfrentar a revisão pelos pares quanto a procedimentos, significância, originalidade, validade etc." (Tripp, 2005, p. 447), sendo, no entanto, distinta de outras metodologias em educação por ter um caráter intervencionista na prática, buscar o envolvimento tanto de alunos como de professores (subvertendo a lógica binarista que estabelece sujeitos e objetos de pesquisa) e, por fim, é voltada para a criação de soluções que, por si sós, podem gerar novos problemas de pesquisa. Tripp (2005) avança na distinção entre metodologias de pesquisa e afirma que “como a pesquisa-ação ocorre em cenários sociais não manipulados, ela não segue os cânones de variáveis controladas comuns à pesquisa científica, de modo que pode ser chamada mais geralmente de intervencionista do que mais estritamente experimental" (Idem, p. 448).

A pesquisa-ação em interpretação de conferências tem um caráter tanto mais relevante já que, como afirma Pöchhacker (2010c, p. 4, apud Hale \& Napier, 2014, p. 176), “apesar do grande aumento no número de cursos de formação de intérpretes de conferência em âmbito universitário, ainda sabemos muito pouco acerca do que acontece em sala de aula" ${ }^{\prime \prime}$.

A pesquisa-ação apresenta uma série de benefícios elencados por Hale \& Napier (2014, p. 187), tais como “a obtenção de melhorias duradouras na atividade de ensino bem como uma melhor compreensão de como este se dá e a busca pelo desenvolvimento de atividades mais

\footnotetext{
${ }^{9}$ For all the steep rise in the number of university-level interpreter training programs worldwide, we know very little about what actually transpires in the interpreting classroom.
} 
centradas no aluno"10. Para o professor, o benefício é igualmente relevante, segundo as autoras: "o professor passa a compreender a pesquisa-ação como um enquadramento natural para engendrar mecanismos de mudança no contexto educacional e, além disso, sua capacidade de reflexão e monitoramento de sua própria prática ficam aguçados", o que resulta em um fazer docente melhor (Hale \& Napier, 2014, p. 187) ${ }^{11}$.

Como se dá a organização de um projeto de pesquisa-ação? Hale \& Napier (2014) fazem eco ao desenvolvimento da metodologia na área da educação em geral e ponderam que é necessário desenvolver um plano de pesquisa em que o problema identificado é descrito. Em seguida, é necessário verificar como o problema já vem sendo narrado no campo de estudos e na realidade social em que está inserido. No caso da pesquisa da qual emerge o presente artigo, a questão que se impunha tinha a ver com a oferta insuficiente de mecanismos que possam munir os alunos de interpretação com capacidade de desenvolvimento de aprendizagem autônoma e de exploração das suas limitações e possibilidades de aprender. Essa percepção, presente desde a época em que a autora era ela própria aluna de formação do curso em questão, passou a se tornar uma preocupação cada vez mais constante, não apenas pela identificação de perfis de alunos do curso (alunos com expectativa de realização de um curso no qual dessem conta de todo o conteúdo a ser aprendido e treinado apenas durante as horas de prática em sala de aula).

\footnotetext{
10 (1) lasting improvements in teaching in terms of deeper understanding of teaching and willingness to employ more innovative teaching strategies, (2) a shift towards more student-centred teaching approaches and a better understanding of student's needs.

${ }^{11}[\ldots]$ teachers' development of action research abilities and recognition of action research as a natural framework for the educational change process, (4) improved capacity and competence to reflect upon, and monitor quality of own teaching.
} 


\subsection{A mudança curricular como inspiração para a pesquisa-ação}

O estopim prático para a reflexão com vistas à intervenção na prática adveio da reestruturação curricular concebida no ano de 2015 e implementada pela primeira vez no ano de 2016 na PUC-Rio, reestruturação essa que levava em conta, como tema transversal, o desenvolvimento da capacidade de aprender a aprender. Com isso, desenvolveu-se em nível curricular a abertura necessária para pensar mecanismos de aprimoramento da autonomia do aluno, levasse ela apenas a uma melhora do desempenho em sala de aula ou conduzisse a modificações mais profundas no processo de aprendizagem (com vistas, por exemplo, à prática deliberada).

Mas quais mecanismos seriam então engendrados para a realização de uma eventual reforma micro-curricular em determinadas disciplinas? Correu-se às pesquisas desenvolvidas no âmbito da discussão acerca do aprender a aprender e também acerca da produção de material de análise de percepções acerca da aprendizagem autônoma e refletida (Horvárth, 2005). As primeiras reflexões foram externadas em congresso acadêmico, o que permitiu ampliar o círculo de discussão e fomentou novas perguntas voltadas ao problema de pesquisa-ação.

Em um terceiro momento, no qual é importante decidir a que ação ele será "pareado", optou-se por proceder à inovação curricular no contexto da disciplina "Estudos da Interpretação". As razões pelas quais essa disciplina foi escolhida tiveram a ver com o desafio em unir a discussão histórico-teórica inerente a essa disciplina com um momento de reflexão mais fundamental acerca das possibilidades de aprender a aprender, tomando como inspiração os grandes nomes da interpretação de 
conferência na contemporaneidade. A partir da adaptação da ementa original às demandas do desenvolvimento de aspectos do aprender a aprender, procedeu-se ao quarto momento, em que deve haver um planejamento quanto à implementação da mudança (curricular).

A primeira mudança deu-se ao nível macro-curricular: a disciplina que até 2015 se chamava "Princípios teórico-pragmáticos" passou a se chamar "Estudos da Interpretação". A modificação, como mencionado anteriormente, inscreveu-se em uma reorientação curricular de amplas proporções com vistas não apenas a melhor atender as demandas de mercado, mas também corresponder à proposta do curso de fornecer aos alunos aspectos teóricos estruturais da área de conhecimento. A ementa original previa um curso de 30 horas/ aula (divididas em 15 encontros ao longo do semestre) dedicado à apresentação e análise de aspectos históricos e teóricos da interpretação bem como à preparação da monografia. A ementa de 2015 foi dividida, portanto, em três blocos:

- o primeiro bloco, basilar, composto dos seguintes conteúdos: história da interpretação no mundo e no Brasil, elementos basilares da interpretação e perfil do intérprete, bem como abordagens e modelos que explicam os esforços, as táticas e estratégias envolvidos no ato da interpretação;

- o segundo bloco, dividido entre sessões no início e final do semestre, de aulas práticas sobre a confecção de monografias;

- e o terceiro bloco que, em chamadas 'aulas temáticas', desenvolveu elementos como 'memória', 'expertise', 'criatividade' e 'profissionalismo e cooperação'.

A implementação da ementa adaptada deu-se no segundo semestre de 2016, em um contexto em que diversas outras disciplinas do curso 
também haviam passado por modificações, em especial quanto à progressão e materiais didáticos utilizados. Havia, portanto, a expectativa de que a ementa da nova disciplina teórica, agora intitulada "Estudos da Interpretação", atendesse aos novos objetivos do curso. No entanto, ao final do semestre, a professora percebeu algumas dificuldades que motivaram a ideia de transformar a ementa em objeto de pesquisa-ação e, com isso, permitir que esta fosse objeto de reflexão e transformação. As dificuldades residiram, após avaliação das atividades, nos seguintes aspectos:

- a divisão em blocos dissociou a monografia de outros aspectos teóricos abordados - o que que era para ser uma ajuda, tornou-se mais uma dificuldade no âmbito da disciplina;

- a divisão entre um bloco histórico-teórico e um bloco 'temático' pareceu hierarquizar de forma arbitrária a importância dos assuntos;

- os alunos pareceram não ver utilidade prática nas atividades propostas durante o semestre (resenhas críticas de cada texto).

Essa situação inicial engendrou a ideia de modificação da ementa a partir da inspiração investigativa da pesquisa-ação. $O$ objetivo da modificação seria: que os alunos vissem maior significado nos conteúdos aprendidos, que conhecessem os teóricos que haviam concebido as teorias em vez de terem contato com as teorias apenas e que a cada input teórico tivessem a oportunidade de refletir sobre a própria aprendizagem e também interagissem com a técnica da simultânea.

O desenvolvimento em espiral da pesquisa-ação requer, e neste caso também requereu, um retorno reflexivo ao processo após a implementação. A justificativa do retorno à reflexão pós-implementação emerge dos elementos inerentes à condução da pesquisa, em especial o respeito à ideia de que o ambiente social da pesquisa está sujeito a inúmeras externalidades 
que interferem na intervenção e, por conseguinte, nos resultados planejados. A reflexão sobre o projeto de pesquisa-ação resultará em nova fase da pesquisa-ação. No caso específico apresentado aqui, após a implementação da nova ementa, identificaram-se alguns recursos necessários para oferecer suporte ao processo de aprendizagem autônoma dos alunos (Hale \& Napier, 2014, pp. 187-188).

\section{Da prática à práxis: incorporação, no contexto da disciplina "Estudos da Interpretação", da aprendizagem autônoma baseada na ideia do 'aprender a aprender'}

A partir, portanto, da inspiração epistemológica e metodológica da pesquisa-ação e considerando a possibilidade de aprimoramento da prática a partir do fomento à resolução de problemas, do desenvolvimento de uma pedagogia centrada no aluno e do foco em uma melhora reflexiva da atividade de ensino-aprendizagem, buscamos desenvolver o conhecimento na área denominada 'aprender a aprender'.

A inspiração emergiu da ideia de que o ensino-aprendizagem da atividade interpretatória na atualidade está estreitamente relacionada à integração de novas tecnologias não apenas para o preparo de futuros profissionais, mas também como ferramentas que possibilitam o aprendizado em qualquer lugar. Assim, considerou-se necessário incluir no contexto da formação o mapeamento, aplicação e monitoramento/ avaliação de mecanismos de organização da progressão da aprendizagem em interpretação levando em consideração o aluno como um todo, um aprendiz que dispõe de múltiplos canais de acesso à realidade social e que pode fazer uso deles para seu próprio aprimoramento ao longo da sua vida 
profissional. A ideia da 'aprendizagem ao longo da vida' pode ser fomentada em sala de aula tanto sob forma de tema transversal como na construção de conteúdos e didáticas de forma que, ao longo do processo de formação formal, o aluno desenvolva as habilidades necessárias ao automonitoramento do seu trabalho, à interação crítica e reflexiva com o texto e o monitoramento das suas deficiências linguísticas, de conhecimento ou técnicas.

Os requisitos para uma aprendizagem autônoma têm a ver com aspectos como, primeiramente, sua capacidade de reflexão - a capacidade de pensar acerca do processo de aprendizagem de forma consciente. Também têm a ver com questões de postura e atitude - o/a aluno/a deve ser estimulado/a a tomar decisões conscientes em relação à organização (onde, quando, com quem) e ao conteúdo (o quê, por quê) de sua prática e de seu processo de aprendizagem.

A aprendizagem autônoma também deve estar imbuída de autorreflexão, ou seja, da capacidade de pensar sobre si e da habilidade a autopercepção crítica na condição de aprendiz. Em penúltimo lugar, a aprendizagem autônoma requer a capacidade de avaliação/ de pensar sobre o curso. A avaliação implica pensar criticamente aspectos do curso, dos estágios, dos exercícios propostos, observações, interações docentediscente bem como discente-discente. Por fim, é importante que a aprendizagem autônoma promova a autoavaliação, ou seja, a capacidade de refletir sobre o resultado. A autoavaliação deverá ser ao mesmo tempo realista e multifacetada, processo pelo qual o aprendiz investiga as razões dos seus erros (e acertos) e, assim, estabelece novas tarefas e encontra novas estratégias de aprendizagem (Ficchi, 1999; Horvárth, 2005; Lee, 2005). A pesquisa-ação levou em consideração que o empenho da disposição da 
aprendizagem contínua no contexto do ensino de tradução no século XXI constitui-se fundamental para a formação de profissionais que atendam a demandas de qualidade impostas pela atividade laboral na área. A percepção da qualidade está diretamente associada à capacidade do tradutor de aprimorar as técnicas tradutórias e expandir seu conhecimento através da prática (Collados \& Becerra, 2005).

Com base nessas reflexões desenvolvidas a partir da própria prática como intérprete e também a partir das reflexões contidas na literatura especializada e angariadas em debates entre pares, desenvolveu-se a seguinte série de modificações gerais na ementa original:

- a ementa de Estudos da Interpretação passou a contar com depoimentos oralizados de intérpretes profissionais em complementação às leituras tidas como canônicas para a história e memória do campo. Com isso, objetivou-se aproximar os grandes intérpretes da realidade do aprendiz, mostrando que - com sua voz, hesitações e opiniões - os grandes 'exemplos' na área da interpretação eram ao fim e ao cabo profissionais com uma trajetória de vida com pontos de proximidade em relação à trajetória dos aprendizes;

- do ponto de vista da divisão de insumos, a ementa foi dividida entre momentos de input e reflexão e sessões sempre voltadas ao 'aprender a aprender' devotado a algum aspecto da vida prática do intérpreteaprendiz;

- do ponto de vista didático, procedeu-se às discussões em grupo, interpretação simultânea de áudios da temática da interpretação e momentos de reflexão individual e em dupla sobre formas de aprender e aprimorar determinadas sub-habilidades da interpretação e também aspectos sociointeracionais, como as dificuldades de trabalhar em dupla. 
Um dos resultados da primeira experiência de alteração da proposta curricular teve a ver com a atualização das próprias leituras em estudos da interpretação e com a utilização mais estratégica dos recursos teóricos com vistas à sua implementação prática. Outros resultados preliminares, do ponto de vista docente, tiveram a ver com a elucidação da necessidade do estudo em casa e da ideia de que aprender a aprender seria um movimento contínuo, tal como evidenciado na ementa. Os trabalhos finais dos alunos infelizmente não evidenciaram esses elementos, já que a disciplina exerce dupla função: a de apresentar aspectos teóricos do campo dos estudos da interpretação e também preparar o aluno para a confecção da monografia de final de curso, elemento mandatório à conclusão da especialização. Nesse sentido, o desenvolvimento da autoconscientização deu-se nas conversas em sala de aula, e a experiência mostrou que novas alterações à ementa seriam uma forma de aprimorar aspectos da disciplina.

\title{
5. Considerações finais
}

A interpretação de conferências

\begin{abstract}
é uma atividade interlingual e transcultural que exige um alto nível de competência em multitasking em operações cognitivas e imediatez em processamento e transferência de conhecimento. O desenvolvimento da competência interpretatória requer esforços tanto do instrutor quanto do aluno (Wang, 2015, p.66) ${ }^{12}$.
\end{abstract}

\footnotetext{
12 Interpreting is an interlingual and crosscultural activity that requires a high level of competence in multitasking in cognitive operations and immediacy in information processing and transference. Developing interpreting competence requires both instructor and student effort.
} 
Nesse sentido, o desenvolvimento de uma sala de aula reflexiva e voltada para a práxis é fundamental para o aperfeiçoamento do saber-fazer pedagógico, da construção profissional de futuros intérpretes e da constituição do saber no campo dos estudos da interpretação. A partir dessa perspectiva, os currículos dos cursos de formação são um objeto central de estudo, haja vista definirem o escopo, a profundidade e o ordenamento dos conteúdos a serem trabalhados com os alunos.

A presente pesquisa se insere no contexto maior da reformulação curricular do curso de pós-graduação lato sensu em formação de intérpretes de conferências da PUC-Rio: nesse contexto, houve não apenas uma mudança na ordem dos conteúdos, mas também no objetivo e forma de abordá-los. O presente trabalho apresenta aspectos da adaptação da ementa da disciplina Estudos da Interpretação a partir da inspiração metodológica da pesquisa-ação e com o objetivo de dar a ela não apenas um caráter teórico-prático, mas também uma pedagogia mais centrada no aluno. A inspiração epistemológica e metodológica da pesquisa-ação evidenciou-se em algumas etapas do processo de transformação curricular conforme a lógica da pesquisa-ação: o primeiro passo foi a constatação da insuficiência tanto dos conteúdos quanto da didática propostos pela ementa 'antiga' diante de demandas tanto do curso quanto dos alunos. Ambas as expectativas convergiam para uma seleção de conteúdos e abordagem pedagógica que mirassem em uma integração maior entre teoria e prática e que fornecessem aos alunos instrumentos para reflexão e práticas autônomas.

A partir da fase inicial de reflexão e identificação de insuficiências, recorreu-se à literatura especializada com o intuito de (1) identificar o mesmo fenômeno em outros settings e (2) buscar embasamento teórico e 
evidências práticas para caminhos de transformação do status quo. A segunda etapa, também orientada pela pesquisa-ação, foi dedicada à reorganização dos conteúdos do semestre, à busca de uma variabilidade de materiais didáticos (textos e áudios) e também à definição de formas de trabalho em sala de aula (dinâmicas didáticas como trabalho individual, em dupla e em grupo a partir do esquema think-pair-share) que permitissem alcançar o objetivo. O 'diário de classe' compartilhado em nuvem e disponível a todo o corpo docente, como é prática no curso, foi utilizado como fonte de reflexão da prática pedagógica. Também foram feitos registros escritos individuais das percepções extraídas da prática pedagógica. Os registros, ainda que idealmente devessem ser complementados com uma avaliação do semestre por parte dos alunos, atendem às demandas de confiabilidade com que a pesquisa-ação foi desenvolvida. Realizados todos os passos anteriores, procedeu-se ao estudo dos erros e acertos a partir da avaliação tanto do processo de aprendizagem desenvolvido ao longo do semestre como dos produtos entregues pelos alunos. Tais avaliações - do processo e do(s) produto(s) - servem à conclusão do processo de pesquisa e à reflexão pós-intervenção que resulta no início de uma nova fase investigativa.

Muitos questionamentos permanecem em aberto, convidando ao estabelecimento de novos objetivos no contexto da pesquisa-ação: como integrar novos conteúdos oriundos do desenvolvimento científico do campo dos estudos da interpretação e adaptá-los às necessidades dos alunos para que desenvolvam uma prática do ofício mais reflexiva? Que outros aspectos da aprendizagem autônoma e da perspectiva do lifelong learning ainda precisam constar da ementa? Quais conteúdos podem ser secundarizados no programa de curso de forma que este não seja 
descaracterizado? Que outras estratégias de ensino-aprendizagem, inclusive mediadas pelas chamadas 'novas tecnologias', podem ser interessantes para os alunos no contexto da aprendizagem ao longo da vida? Em que medida a adaptação de conteúdos interfere até mesmo na progressão pedagógica? Que instrumentos permitiriam a avaliação mais precisa desse aspecto do ensino-aprendizagem? ${ }^{13}$

Como resultado preliminar, é possível apontar que, por um lado, o enquadramento epistemológico e metodológico da pesquisa-ação mostrou ser aquele que melhor reflete a possibilidade de associar teoria e prática ao cotidiano da sala de aula. O projeto de adaptação da ementa calcado em aspectos da pesquisa-ação mostrou que a dimensão da aprendizagem contínua não apenas pode ser um aspecto a ser trabalhado em sala de aula, mas também tem uma dimensão transversal já que está inter-relacionada a aspectos mais amplos da formação de intérpretes, à relação com as ementas e conteúdos de outras disciplinas do próprio curso, estilos e abordagens de ensino-aprendizagem, ethos do curso e formas de avaliação de um modo geral (Hale \& Napier, 2014, p. 191).

A incorporação da preocupação manifesta com a aprendizagem autônoma e contínua pautou tanto a escolha dos conteúdos, como seu ordenamento e as formas de avaliação da produção dos alunos. Com isso, o foco da disciplina adquiriu um caráter mais evidentemente teórico-prático e suscitou novos questionamentos e tópicos de pesquisa. A aprendizagem centrada no aluno busca instigar neles e nelas a ideia de que estão em processo constante de formação cônscios de que, para além de conteúdos, a aprendizagem de práticas e hábitos faz com que tornem a prática

\footnotetext{
${ }^{13}$ ver Hale \& Napier, 2014.
} 
tradutória em prática refletida - práxis - e potencializem suas capacidades linguísticas e cognitivas ao longo da carreira.

A presente reflexão baseou-se na desafiadora atividade pedagógica de aproximar alunos da práxis - da prática refletida - e a pesquisa-ação deve ser comprometida com a reflexão e produção acadêmica em torno das questões do seu tempo.

\section{Referências}

ADAMS, A. Developing expertise through a deliberate practice project. International Journal of Interpreter Education, 3, pp. 16-27, 2011. COHEN, L, MANION, L, MORRISON, K. Action research. In: Research Methods in Education. 6a. Ed. Nova York: Routledge, 2007, pp. 297-312. COLLADOS, A \& BECERRA, O.G. Quality. In: The Routledge Handbook of Interpreting. London: Routledge. 2015.

ERICSSON, K.A. Expertise in interpreting. Interpreting 5 (2), pp. 187-220, 2000.

FICCHI, V. Learning consecutive interpretation. Interpreting 5 (2), 1999. GILE, D. Basic Concepts and Models for Interpreter and Translator Training. Edição revisada, Amsterdam/ Philadelphia: John Benjamins, 2009, 283p.

HALE, S., NAPIER, J. Research on interpreting education and assessment in Research Methods in Interpreting - a practical resource. Nova York: Bloomsbury, 2014. pp.175-208.

HERBERT, J. The interpreter's handbook: how to become a conference interpreter. Editora desconhecida, 1957. 
HORVÁRTH, I. The cognitive components of autonomous learning in postgraduate interpreter training. Supporting independent English language learning in the 21st century: proceedings of the Independent Learning Association Conference Inaugural. 2005 In: < www.independentlearning.org/uploads/100836/HOR05034.pdf > (Acesso em 20 de novembro 2017).

KROUSE, L. Cooperative learning applied to interpreting education. International Journal of Interpreter Education, 2, pp. 180-200, 2010.

LEE, Y-H. Self-assessment as an Autonomous Learning Tool in an Interpretation Classroom. Meta: journal des traducteurs / Meta: Translators' Journal, vol. 50, $\mathrm{n}^{\circ} 4,2005$.

PÖCHHACKER, F. Introducing Interpreting Studies. New York: Routledge, 2007.

$\mathrm{SHIH}, \mathrm{C}$. Learning from writing reflective learning journals in a theorybased translation module - student's perspectives. The Interpreter and Translator Trainer, 5 (2), pp. 309-324, 2011.

TAYLOR-BOULADON, V. Conference Interpreting - principles and practice. Adelaide: Crawford House, 2000.

TRIPP, D. Pesquisa-ação: uma introdução metodológica. Educação e Pesquisa, 31, 3, pp. 443-466, 2005.

WANG, B. Bridging the gap between interpreting classrooms and realworld interpreting. International Journal of Interpreter Education, 7 (1), pp. 65-73, 2015. 


\title{
Resumo
}

Segundo Pöchhacker (2007), a reflexão acerca das práticas de ensinoaprendizagem no contexto da formação de intérpretes de conferência tem sido parte fundamental da evolução do próprio ofício ao longo das décadas. Este artigo tem como objetivo apresentar a metodologia da pesquisa-ação e sustentar a sua relevância no contexto dos estudos da interpretação através da pesquisa em sala de aula com o objetivo de fomentar o desenvolvimento de pensamento crítico e da aprendizagem autônoma de alunos de interpretação.

Palavras-chave: pesquisa-ação; aprendizagem autônoma; didática da interpretação de conferência

\begin{abstract}
According to Pöchhacker (2007) the reflection upon teaching-learning practices in the context of conference interpreter training has played a fundamental role in the development of the profession itself. This article aims at presenting a methodological approach called action research methodology and claiming its relevance for interpreting studies through the presentation of a classroom research project dedicated to fostering critical thinking and autonomous learning of conference interpreter trainees.

Keywords: action research; autonomous learning; didactics in conference interpreter training
\end{abstract}

